\title{
A ANÁLISE NARRATIVA COMO POSSIBILIDADE DE UMA LINGUAGEM PARA EXPERIÊNCIA
}

ADRIANA BARBOSA DE OLIVEIRA

Universidade Federal de Mato Grosso do Sul

MARILENA BITTAR

Universidade Federal de Mato Grosso do Sul

\section{LUZIA APARECIDA DE SOUZA}

Universidade Federal de Mato Grosso do Sul

Nesse artigo, buscamos apresentar o percurso narrativo desenvolvido em uma pesquisa que teve como interesse investigar as percepções de estudantes de cursos de Licenciatura em Matemática, acerca de sua formação, para atuarem como professores de Matemática na educação básica. Trata-se de uma pesquisa de doutorado que mobilizou o uso de narrativas, na perspectiva de Antonio Bolívar, para a produção de dados e escritos sobre experiência e alteridade, desenvolvidos por Jorge Larrosa e Carlos Skliar, para o trabalho de composição com eles. Neste texto, apresentamos os olhares das pesquisadoras sobre o uso da análise narrativa como possibilidade para uma escrita sobre experiências.

Palavras-chave: Análise narrativa. Experiências. Pesquisa.

NARRATIVE ANALYSIS AS A POSSIBILITY FOR A LANGUAGE TO EXPERIENCE

In this article we seek to present the narrative course developed in a research whose interest was to investigate the perceptions of undergraduate students in Mathematics about their training to act as teachers in basic education. This is a part of the doctoral research that used the study of Narratives, from Antonio Bolivar's perspective, for the production of data and the writings on experience and otherness, developed by Jorge Larrosa and Carlos Skliar, for the work of composition with the data. Specifically, in this text we present the female researchers' views on the use of narrative analysis as a possibility for writing about experiences.

Keywords: Narrative analysis. Experiences. Research. 


\section{RESUMEN EL ANÁLISIS NARRATIVO COMO POSIBILIDAD DE UN LENGUAJE PARA EXPERIENCIA}

En ese artículo buscamos presentar la ruta narrativa desarrollada en una investigación donde el interés es investigar las percepciones de estudiantes de los cursos de Licenciatura en Matemática, sobre su formación para actuaren como profesores en la enseñanza básica. El estudio tratase de una investigación de doctorado que movilizó el uso de Narrativas, en el punto de vista de Antonio Bolívar, para la producción de los datos y los escritos acerca de experiencia y alteridad, desarrollados por Jorge Larrosa y Carlos Skliar, para el trabajo de composición con ellos. En ese texto presentamos las perspectivas de las investigadoras acerca del uso del análisis narrativo como posibilidad para una escrita acerca de las experiencias.

Palabras-clave: Análisis narrativo. Experiencias. Investigación.

E todos os dias somos convidados a falar e a escutar, a ler e a escrever, a participar ativamente nesse gigantesco maquinário de fabricação e de circulação de informes, de projetos, de textos. A pergunta é: em que língua? E também: pode ser essa língua a nossa língua?

Jorge Larrosa (2016, p. 58)

Neste artigo, escolhemos apresentar a narrativa de cada uma de nós sobre o processo de pesquisa vivenciado, escolhendo, para isso, o tom que julgasse ser o mais adequado e que melhor sinalizasse os desdobramentos de nosso encontro.

Assim, nossa primeira voz se dá em: Se há mais de um, há que ser um encontro! -, narrativa produzida por Luzia, coorientadora dessa tese. No segundo texto - Uma conversa sobre a produção de um grito (substantivo-tese, verbo - pesquisar) -, Adriana conta a sua travessia de doutoranda. Fechando o artigo, temos a fala de Marilena, orientadora deste estudo, em: Outro lado da história? Não, outra história!

\section{Se há mais de um, há que ser um encontro!}

Este texto trata de distintos movimentos em torno de um exercício de análise narrativa.
Movimentos de formação que deslocam orientadora, coorientadora e orientanda de seus lugares de fala e ação e que envolvem as três e várias outras pessoas vinculadas a dois grupos de pesquisa (DDMat - Didática da Matemática e HEMEP - História da Educação Matemática em Pesquisa), em um processo fundamental de estranhamento, discussão e, por que não dizer, cuidado de si.

Adriana, assim como Marilena e eu, somos professoras da Universidade Federal de Mato Grosso do Sul e era assim que eu a conhecia até o início de 2015. Foi quando começou não somente o processo de doutoramento de Adriana, como o próprio curso de Doutorado em Educação Matemática nessa instituição e, também, minha atuação como coordenadora desse Programa. Era, portanto, um ano cheio de novas atribuições e desafios para todas nós.

Disciplinas da Pós-Graduação, exercícios de estranhamento e sensibilização dos sentidos. Lembro-me de ouvir algumas vezes o relato das angústias geradas nas discussões em sala. Lembro-me de perceber, na primeira turma de doutorado, diferentes tipos de abertura ao diferente e à leitura como formação. 
Larrosa (2007) lembra que, neste caso, não se trata de ler um texto (aqui tomado em toda a amplitude permitida pela virada hermenêutica, no sentido de ser tudo aquilo a que atribuímos significado), em busca do que queremos, buscamos ou já dizemos, mas de colocarse na leitura aberta ao que não se busca, ao que não tem interesse a priori ao que, de fato, é do outro e não uma projeção de si sobre o outro. Já nesse sentido da leitura como formação, percebi Adriana-doutoranda em Educação Matemática envolvida e envolvendo terceiros. Agora, era Giovani (seu esposo) quem já sinalizava: "olha para este comercial, veja como eles focam nas relações e não nos produtos!" Não sei se era exatamente assim que ele dizia, mas é assim que teço essa história, quando me lembro da Adriana contando sobre o Giovani. Enquanto ela falava dele, eu observava como ela fiava e tecia (nos termos de Walter Benjamin), a partir das conversas iniciadas em sala de aula.

A formação de uma pesquisa, ainda que tomada na perspectiva cartográfica, tem um traçado mais familiar: ou se tem uma questão inicial, ou se coloca atento ao aparecimento desta, ao longo da investigação; ou se empresta a nomenclatura e os procedimentos de uma metodologia, ou se concebe que se constrói uma metodologia singular na travessia..., mas a formação de um(a) pesquisador(a) é sempre um processo peculiar.

Se a expressão de Adriana, no início das aulas, era de ânimo, uma quase felicidade mesmo, de interesse, esta foi se alterando com o passar do tempo. Adriana vai se tornando reticente em falar sobre seu trabalho, vai mostrando (antes no olhar que nas palavras) uma angústia sem fim: "não quero mais fazer a pesquisa que me propus fazer! E não sei o que quero fazer!" Foram meses antes que estas frases escapassem dela e falo em escape, pois era visível o esforço de seu corpo em segurá-las.
Aqui começa um processo de formação que não aparece na tese: o meu. Que ideia de ciência e academia temos propagado ou ajudado a manter, quando afastamos os diferentes sentidos e subjetividades que atravessam qualquer processo humano como o investigativo? Trabalhar há dezoito anos com história oral, entrevistas, narrativas, levou-me a cuidar de alguns fatores, corriqueiramente, por sabê-los pontos chave ou problemáticos, mas também me fez naturalizar a noção de subjetividade, a ponto de deixar de problematizar o modo próprio, singular, com que cada um de nós se constrói na/pela pesquisa. Tomar o outro como texto tem me ajudado em um movimento de estranhamento fundamental à produção de conhecimentos e não mais, ou somente, de reconhecimentos. Lembrada por Adriana e outr@s orientand@s que não somos somente nós, mas nós e nossas circunstâncias, acabei me tornando interlocutora de uma angústia e, por que não dizer, de uma violência: como dizer à orientadora e amiga de anos que não queria mais estudar aquilo que nesses anos todos ela se dedicou com tanta seriedade a estudar?

Esta foi a primeira de várias angústias compartilhadas e que me fizeram estranhar diferentes tipos de relações que temos fomentado, por vezes sem saber, na pós-graduação. Coragem, desabafo, compreensão, orientação, coorientação. E novos processos eram construídos e nos construíam. Como ouvir inúmeras vezes as entrevistas já realizadas pôde ajudar na construção de uma nova questão de pesquisa? Como é possivel explicitar um interesse em não categorizar e generalizar e produzir um texto marcado por ambas as coisas? Como é possivel defender uma formação que considere as diferenças e construir um texto absolutamente prescritivo? Adriana construía-se narrativamente diante de mim como uma farsa: conclusões 
rápidas acompanhadas de um longo processo de desconstrução. Quando foi que a coerência de um texto escrito, limitado, temático, foi transferida para um ser humano-texto? Se somos atravessados, marcados por inúmeras coisas e contextos, se nós e/com nossas circunstâncias nos alteramos diariamente, como poderíamos não ser contraditórios? Dar-se conta disso não podia ser o fim de um projeto, um doutorado ou uma carreira, como cogitava Adriana. Cabia assumir a simultaneidade de oposições que nos constituem e seguir. Seguimos.

Lembro-me que uma das discussões que chamou sua atenção, naquelas aulas, foi a provocada por Sônia Clareto: o importante não é chegar ao final de uma pesquisa com respostas, mas com questões! Não sabemos se problematizar é algo que se "aprende", parece mais a decorrência de um modo de se construir no e de construir o mundo.

Como efetivamente falar com os entrevistados e não por eles? Embora essa questão seja muito comum, em início de orientações, é interessante ressaltar que o modo como ela afetava Adriana a levava a assumir posturas como: não vou citar trechos! Se defendo que as entrevistas devem ser lidas integralmente, por que eu mesma criaria opções ao leitor para não fazê-lo?

Um enfrentamento que se fez presente, ao longo deste doutorado, foi a escrita. O formato comumente mobilizado para uma tese parecia não contribuir para dizer desse processo caótico que é um processo de formação. Talvez nenhum formato contribua, ao fixar em si uma linearidade própria da escrita. Talvez o plano seja criar fissuras nessa linearidade, produzir respiradouros, ao preservar linhas e entrelinhas. Talvez um caminho seja pensar a forma como um conteúdo alinhado politicamente a um modo de ver/construir o mundo e, nesse sentido, como um modo pró- prio de soltar a voz, gritar na esperança de que este grito ecoe.

A dificuldade de Adriana em construir esse caminho, esse modo próprio de soltar a voz, não é uma especificidade sua, mas algo tão comum na Pós-Graduação que, uma vez mais, tem me movimentado como pesquisadora (e coordenadora do PPGEdumat), nos últimos anos, a ponto de buscar interlocuções com a Psicologia sobre bloqueios na escrita (com Robson Cruz) e sobre "a educação pelo sofrimento" na Pós-Graduação (com Tiago Ravanello). Quais violências têm ocorrido silenciosamente nas relações de orientação e de escrita? Ao buscar explicitar algo que parece ser uma identidade para grupos de pesquisa, acaba-se produzindo uma noção equivocada de que "nesse grupo se pesquisa assim, se escreve assim, se defende isso" e, ao matar a diferença, acaba-se criando um movimento de defesa de territórios, de competição, de entendimento de que não há, em grupos de pesquisa, espaço para desacordos, questionamentos, invenções, inovações. Esse cenário é sustentado por violências diárias aos sentidos, aos modos próprios de constituição do mundo e de si e quebrar esse ciclo parece estar além da racionalidade, mas da busca por explorar as diferentes sensibilidades de mundo. Nesse sentido, argumento que além de um texto teórico acerca de um tipo de análise, as histórias que narramos neste texto evidenciam a importância da análise narrativa na formação de pesquisadores, sejam eles orientandos ou orientadores.

Quantas Adriana são necessárias para constituir uma tese? Com essa provocação, feita ao longo dos últimos anos a esta orientanda, os convido a "escutar", com o tom que cada um quiser dar em sua leitura, um pouco mais sobre duas outras travessias vinculadas à produção não somente de uma tese, mas de pelo menos três pesquisadoras. 
Uma conversa sobre a produção de um grito (substantivo-tese, verbo-pesquisar)

Em março de 2015, dei início ao meu processo de doutoramento no Programa de Pós-Graduação em Educação Matemática da Universidade Federal de Mato do Grosso do Sul. Em setembro de 2018, após eternos e dolorosos três anos e seis meses, concluí esse processo. Hoje, cinquenta e oito dias depois do término, aventuro-me novamente pelos meandros e encantos das palavras e sinto, como no início, que elas continuam se escondendo de mim.

Venho aqui movida pelo desejo de contar a experiência vivida nesse processo, mesmo sabendo que, da perspectiva Larrosiana que me coloco, experiências conjugam o verbo sentir. O contar, narrar, relatar... experiências, são só invenções nossas enquanto pesquisadores que, mesmo ricos delas (nem sempre!), ainda continuamos limitados à oralidade e ao texto escrito, em nossos modos de comunicação. No entanto, mesmo certa de que o que faço aqui será distinto do que senti, ainda acredito que posso experienciar ao tentar narrar o experienciado e pretender que você possa, comigo ou a partir de mim, mobilizar sentidos outros. Minha história é sobre outra história. Trago nesse texto potencialidades da análise narrativa no exercício de uma linguagem para a experiência.

Minha pesquisa insere-se na temática da Formação de Professores de Matemática. Um campo fértil e abundante para a realização de estudos no campo da Educação Matemática. Meu interesse, desde que comecei a me inventar enquanto pesquisadora e isso aconteceu ainda no último ano da graduação, o que já ultrapassa uma década, sempre foi pensar sobre a formação do professor de Matemática, talvez instigada pelo anseio de compreender melhor a minha formação, especificamente.
Quando me vi diante da possibilidade de cursar um doutorado não pensei muito diferente, pois a Licenciatura ainda se mantinha viva em mim, talvez agora ainda mais acesa, uma vez que fiz desse ambiente meu local de trabalho. Mudanças em meu projeto de pesquisa aconteceram aos montes, porém em nenhum momento a Licenciatura arredou os pés de meus pensamentos. As questões que me colocava agora eram mais sobre como eu poderia me (re)aproximar dela, nesse novo contexto de pesquisa, vivendo agora a identidade de doutoranda.

Minha opção foi por realizar um estudo com licenciandos de diferentes localidades do país, com o interesse em ouvir deles suas percepções sobre o processo de formação que estavam vivenciando em seus cursos. Não havia um roteiro de entrevista a ser seguido e sim uma vontade de escutá-los, de saber o que eles gostariam de contar sobre suas formações para atuarem como professores de Matemática da educação básica. Assumi ali uma postura investigativa que se interessa "pelos modos como os humanos dão significados ao seu mundo mediante o uso da linguagem" (BOLÍVAR; DOMINGO; FERNÁNDEZ, 2001, p. 53). Para isso, realizei entrevistas, em grupo, em onze instituições públicas de ensino, a saber: Universidade Federal de Mato Grosso do Sul, Universidade Federal de Mato Grosso, Universidade Estadual do Pará, Instituto Federal do Amazonas, Universidade Federal de Rondônia, Universidade Federal do Paraná, Universidade Federal do Rio Grande do Sul, Universidade Federal de Santa Catarina, Universidade de São Paulo, Universidade Federal de Minas Gerais e Universidade Estadual do Rio de Janeiro.

Meu olhar para essas entrevistas deu-se em uma perspectiva de investigação narrativa; não havia ali uma busca por verdades nem um interesse em construí-las. Dediquei-me a evidenciar as idiossincrasias de cada grupo que 
conheci, traçando compreensões acerca de suas particularidades e mantendo-me atenta à dimensão emotiva da experiência expressa pelas narrativas desses estudantes, mantendo-me sempre atenta à fala de Bolívar, Domingos e Fernández (2001, p. 131, tradução minha): “[...] o interesse da pesquisa narrativa não é, em princípio, a generalização formal, mas destacar os significados singulares de certos casos, que - não obstante - podem nos proporcionar uma compreensão de outros semelhantes $[. . .]^{\prime \prime}$.

Ouvir essas narrativas não me permitiu traçar um panorama geral sobre a formação de professores de Matemática no Brasil, e nem era esse o meu objetivo, no entanto, um trabalho de composição com elas me oportunizou um melhor entendimento de tais processos de formação. Mas muito mais do que perceber esses processos, pude me aproximar dessas vozes e ser tocada por elas, de modo a viver a pesquisa como experiência, ou seja, como "aquilo que "nos passa", ou que nos toca, ou que nos acontece, e ao nos passar, nos forma e nos transforma" (LARROSA, 2002, p. 25).

Após a realização das entrevistas, iniciei o trabalho de tratamento dessas informações: transcrevi os áudios e então me dediquei a textualizar as narrativas, buscando deixar o texto, outrora falado, adequado à escrita, mas sem necessariamente eliminar marcas da oralidade e, principalmente, evitando qualquer tipo de manipulação dessas vozes que pudesse alterar o sentido das falas, embora consciente da arduidade desse trabalho.

Assim, nesse processo de manuseio das narrativas, reafirmei impressões que já havia percebido no momento das entrevistas: um transbordar de emoções marcavam as falas

1 No original: “[...] el interés de la investigación narrativa no es, por principio, la generalización formal, sino poner de manifesto los significados singulares de determinados casos, que - no obstante - pueden aportarnos comprensión de otros similares [...]". desses estudantes. Falar sobre o curso foi tomado por muitos como um momento de desabafo, de colocar para fora sentimentos de indignação, tristeza, revolta, alegria, entusiasmo. Era como se houvesse chegado a hora de contar do que se tratava uma formação, para atuar como professor de Matemática, e a abertura do momento permitiu que expusessem suas cicatrizes.

No movimento de escrita que iniciei, também senti a necessidade de destacar essas sensibilidades, pois elas sinalizavam o tom das falas dos estudantes. Eram marcas que eu não poderia deixar de evidenciar, uma vez que havia sido a partir delas que iniciei o movimento teórico de aproximação dos escritos sobre experiência de Jorge Larrosa. O modo como esses licenciandos exteriorizavam suas percepções, afirmando a passionalidade com que muitos se envolviam com o curso, as incertezas quanto à futura profissão, as subjetividades presentes no modo de compreender o processo, a própria fugacidade da formação expressa por eles, conduziam-me a pensar que aquelas eram marcas da experiência, uma vez que é nela que "se descobre a própria fragilidade, a própria vulnerabilidade, a própria ignorância, a própria impotência, o que repetidamente escapa ao nosso saber, ao nosso poder e à nossa vontade" (LARROSA, 2016, p. 42).

Apesar de perceber que essas leituras me auxiliavam em traçar algumas compreensões acerca dessas narrativas, após a produção de alguns textos, na direção de falar sobre a experiência desses estudantes, comecei a perceber que a experiência que me tocava só poderia ser a minha em relação a esses relatos. Por mais que ousasse dizer que muitos deles estivessem, de algum modo, experienciando o curso que vivenciavam, eu não conseguiria, na perspectiva teórica que havia assumido, inferir a experiência do outro. Como coloca Larrosa (2016, p. 10): 
A experiência não é uma realidade, uma coisa, um fato, não é fácil de definir nem de identificar, não pode ser objetivada, não pode ser produzida. E tampouco é um conceito, uma ideia clara e distinta. A experiência é algo que (nos) acontece e que às vezes treme, ou vibra, algo que nos faz pensar, algo que nos faz sofrer ou gozar, algo que luta pela expressão, e que às vezes, algumas vezes, quando cai em mãos de alguém capaz de dar forma a esse tremor, então, somente então, se converte em canto. E esse canto atravessa o tempo e o espaço. E ressoa em outras experiências e em outros tremores e em outros cantos.

O que percebi depois de um longo tempo de convivência com essas narrativas e o envolvimento com esse autor foi que o que estava ao meu alcance era a elaboração de um canto, um ressoar de outra experiência, a minha experiência nesse processo de escuta. Algo havia me acontecido, me tocado, me transformado e foi preciso tempo para que eu me desse conta do ocorrido. 0 tom que eu percebia naquelas vozes eram vibrações do impacto que vivi, os sentimentos que elenquei como deles, eram os meus tremores. A experiência só podia ser a minha. 0 sujeito dessa experiência era quem escrevia aqueles textos e não a terceira pessoa a quem me referia e, diante disso, minha única opção foi assumir esse papel e buscar por "uma linguagem na qual fosse possivel elaborar (com outros) o sentido ou a ausência de sentido do que nos acontece e o sentido ou a ausência de sentido das respostas que isso que nos acontece exige de nós" (LARROSA, 2016, p. 68). Foi nesse momento que a análise narrativa se fez presente em minha escrita. Havia uma história a ser contada, e esta não se encaixava nos moldes acadêmicos que eu estava habituada a seguir. Foi preciso um deslocamento para as margens, e, em algumas situações, até mesmo ignorá-las, riscá-las, preenchê-las.

$\mathrm{Na}$ busca por uma linguagem que fosse mais adequada à natureza dos dados que eu havia produzido entendi que a realização de uma análise narrativa seria um bom caminho para a produção de conhecimento no contexto em que me encontrava, pois Bolivar, Domingo e Fernández (2001, p. 109, tradução minha, grifo do autor) já haviam me dito que:

[...] o resultado de uma análise narrativa é, ao mesmo tempo, uma narração particular, sem aspirar à generalização: por exemplo, um relato histórico, um estudo de caso, uma história de vida, um episódio narrado da vida de uma pessoa em particular. A tarefa do pesquisador, nesse tipo de análise, é configurar os elementos dos dados em uma história que unifique ou dê sentido aos dados, a fim de expressar de maneira autêntica a vida do indivíduo, sem manipular a voz dos participantes.

Nessa perspectiva, vi possibilidades de apresentar um texto em que houvesse espaço para discussões teóricas, emotivas e analíticas. Espaço em que eu pudesse não só apresentar os dados produzidos, mas realizar um trabalho de composição com eles e para isso recorri à construção de uma narrativa ficcional, embora considere difícil traçar uma linha divisória entre realidade e ficção, uma vez que coaduno com a afirmação de Bolívar, Domingo e Fernández (2001, p. 142) de que "todo conhecimento é 'ficção', ou seja, algo construído humanamente".

\section{Uma análise narrativa de narrativas: a busca de si na busca do outro}

O caminho que encontrei para a produção do relatório de tese foi, como dito anteriormente, me colocar como sujeito dessa experiência de falar sobre cursos de Licenciatura em Matemática. E me colocar nesse papel exigiu que eu encontrasse uma voz, ou melhor, a minha voz, um modo que eu conseguisse expressar todos os sentimentos que estavam aflorando em mim nesse movimento de pesquisa. Esse não foi um processo imediato: perceber tudo 
isso levou muito tempo e exigiu uma postura de abertura e disponibilidade para o novo. No entanto, o momento em que consegui fazer ecoar tudo que havia construído até então, foi bastante libertador e intenso. Em pouco tempo, consegui construir a história que apresento na sequência.

Na produção dessa análise narrativa, percebi que seria preciso mobilizar diferentes Adrianas, com diferentes identidades, pois uma única não seria suficiente para trazer todas as discussões pretendidas. Senti a necessidade de mobilizar vozes distintas, que pudessem ecoar em diferentes direções, no campo da formação de professores de Matemática. Assim sendo, há na história uma Adriana, estudante da licenciatura, uma Adriana, pesquisadora/doutoranda e uma Adriana, professora de pós-graduação. Por meio delas, e dos outros personagens que surgem na construção da trama, busquei levantar discussões sobre a formação do professor de matemática, do ponto de vista do acadêmico que vivencia esse processo, e também sobre o desenvolvimento de uma pesquisa e suas implicações, do ponto de vista de um pesquisador.

A história tem início com a Adriana, professora de pós-graduação, no contexto do começo de uma disciplina de metodologia de pesquisa, em que ela sugere a leitura de uma tese, a minha tese, para iniciar um debate sobre estética na produção de trabalhos científicos no campo da Educação Matemática. Após esse convite à leitura, apresento a história que compus com as narrativas produzidas nas entrevistas que realizei e com os autores que estabeleci um diálogo teórico.

Inicio a trama em uma situação de Estágio Supervisionado de um curso de Licenciatura em Matemática, no momento em que a Adriana estudante é levada a adquirir um caderno que será utilizado como um diário de bordo de seu estágio. Tal caderno aparece em várias situa- ções que ela vivencia no curso e acaba sendo usado para o registro de suas inquietações, ao final da história. O cenário é construído com base em minhas recordações em relação aos espaços, imagens, cheiros e sabores de minha formação. Lembranças de situações inusitadas, complicadas, conflitantes, fazem parte dessa narrativa, assim como histórias que ouvi dos estudantes que entrevistei e situações que criei no desejo de problematizar ao máximo o contexto da formação de professores de matemática. No entanto, devo considerar que todas as situações apresentadas se aproximam muito mais da invenção do que da realidade que um dia possa haver existido, uma vez que assumo a perspectiva de que o sujeito se constitui narrativamente ao narrar-se, como bem coloca Souza e Silva (2015, p. 34)

[...] essa memória que acredita-se recorrer ao contar uma história é sempre atual. É uma produção criada no momento em que se conta, ou ainda é a partir de uma pergunta no presente que criamos o passado que só existe no significado atribuído pelo sujeito ao vivido. Ao narrarmos fixamos algumas das possiveis histórias a serem contadas, que serão atualizadas novamente quando uma nova leitura ou uma nova narração for produzida.

Em um determinado dia, a estudante é convidada, pela coordenadora de seu curso, a auxiliar uma pesquisadora que fará uma visita à sua universidade com a intenção de entrevistar alguns estudantes de seu curso. A pesquisadora, também chamada Adriana, vai visitar a instituição, a fim de realizar entrevistas para a sua pesquisa de doutorado. Estabelecido o contato entre as duas Adrianas, elas organizam um encontro para a realização da entrevista. Após esse momento de discussão, a Adriana estudante se vê diante de questões, sobre seu curso, que ela até então não havia levantado. Nesse movimento de tentar compreender o seu processo de formação, ela mantém con- 
tato com a pesquisadora, via e-mail, e passa a realizar leituras, que the são indicadas, sobre a formação de professores de Matemática. Outro deslocamento da acadêmica é organizar um grupo de estudantes da Licenciatura em Matemática, denominado GELIMAT, que vai dar continuidade às discussões que foram levantadas no momento da entrevista com a pesquisadora. 0 grupo passa a se reunir periodicamente e ali são levantadas muitas das problemáticas que envolvem a formação de professores de Matemática, tais como: a dicotomia formação matemática e formação pedagógica, a ausência de diálogo com os professores formadores, o distanciamento entre a matemática do ensino superior e a matemática da educação básica, assim como os estranhamentos que começam a acontecer em relação a essas discussões.

Nessa movimentação da estudante, encontro brecha para apresentar tanto minhas escolhas teóricas como também as narrativas produzidas com os licenciandos que entrevistei. As discussões teóricas aparecem como leituras, pela estudante Adriana, dos textos que a pesquisadora lhe enviou. Apresento o que seria uma conversa da estudante com os autores Jorge Larrosa e Carlos Skliar. Ela tenta, a partir de suas vivências no curso, traçar algumas compreensões sobre os escritos de experiência, bem como se aproximar da ideia de alteridade, que surge como uma possibilidade de discutir o apagamento dos estudantes, em diversas situações, nas narrativas produzidas. Durante todo o processo de leitura, ela tenta articular suas percepções em relação ao curso às elaborações dos autores, realizando tanto aproximações como estranhamentos das ideias discutidas.

Nessa mesma perspectiva de leituras da Adriana, são apresentadas as narrativas que produzi durante as entrevistas. Ela solicita à pesquisadora esse material, na ânsia por sa- ber o que estudantes de outras localidades falam sobre suas formações, e então realiza a leitura desses textos, fazendo apontamentos como notas de margens. Nesse momento, eu recorro a uma fonte que se assemelha à letra cursiva, justamente para enfatizar que se trata das anotações da estudante em relação ao texto.

Após a leitura desses textos e da realização de alguns encontros do grupo GELIMAT, a Adriana estudante, um pouco revoltada com as situações que vivencia no curso e já começando a sofrer algumas intimidações por conta da postura questionadora que começa a assumir, faz uso de seu caderno de estágio para escrever um texto direcionado ao seu curso, mas que também será enviado à pesquisadora, que se interessa em saber sobre suas movimentações, após a participação em sua pesquisa. Faço uso desse texto como sendo algumas das considerações finais que consegui elencar com a produção dessa tese. Faço uso do algumas, por acreditar que esse também pode ser um movimento realizado pelo meu leitor, e ser distinto do que apresento em meu texto. Inclusive, uma de minhas intenções com essa produção é que ela seja tomada como uma abertura para experiências. Desse modo, encerro a trama envolvendo a Adriana estudante.

Na sequência, retomo a situação da aula de pós-graduação e apresento um debate entre a professora Adriana e a sua turma de doutorado, inspirada nas discussões que aconteceram em meu exame de qualificação acerca da estética do meu texto. Além disso, realizo algumas considerações sobre narrativas como produção de conhecimento científico, no campo da educação matemática, como também sobre uma postura ética do pesquisador. Todas essas discussões são realizadas em forma de diálogos entre os participantes dessa aula.

Ao final, no que chamei de Parte II dessa tese, apresento outra narrativa, onde con- 
to todo o meu caminhar durante a realização dessa pesquisa de doutorado. Os encontros e desencontros que ocorreram durante esse processo e as minhas movimentações frente aos acontecimentos. 0 anseio em produzir esse texto foi pensando nos colegas pesquisadores que, assim como eu, vivenciam momentos de angústia e insegurança durante a travessia que pode ser o desenvolvimento de uma pesquisa. A ideia foi construir um texto voz onde houvesse, não só informações assépticas sobre procedimentos de uma pesquisa, livre de emoções e sentimentos que povoam esse momento, mas, principalmente, a voz de uma pesquisadora que se sentiu, por vezes, perdida, insegura e incapaz de realizar essa pesquisa e, que, no entanto, conseguiu construir um caminho e se reinventar nesse processo.

No início desse texto, mencionei a sensação de que as palavras continuavam a fugir de mim, mas talvez o mais adequado fosse pontuar que a minha busca tem sido, há algum tempo, por uma língua/linguagem/escrita em que eu também pudesse me ouvir. Na redação da tese, acreditei ter encerrado essa busca, pois senti ter encontrado a minha linguagem, o meu modo de escrever. Sim e não. Sim, pois a linguagem escolhida me permitiu evidenciar as discussões pretendidas. Não, porque, na busca por uma linguagem para a experiência, seria impossivel determinar uma linguagem única, mesmo que particular, uma vez que uma experiência sempre é singular. $E$, sendo assim, como eu poderia dizer que encontrei a minha linguagem para a experiência se nem ao menos saber das experiências que ainda posso viver?

Assim sendo, reafirmo que a análise narrativa pode ser tomada apenas como uma possibilidade de uma linguagem para experiência. 0 aspecto determinante da escolha de uma linguagem ainda continua sendo a experiência do pesquisador, a sua sensibilidade em perce- ber o que the acontece no seu caminhar, e:

[...] o que quero dizer a você, por último, é que necessitamos de uma língua na qual falar e escutar, ler e escrever seja uma experiência. Singular e singularizadora, plural e pluralizadora, ativa, mas também pessoal, na qual algo nos aconteça, incerta, que não esteja normatizada por nosso saber, nem por nosso poder, nem por nossa vontade, que nunca saibamos de antemão aonde nos leva. (LARROSA, 2016, p. 72)

\section{Outro lado da história? Não, outra história!}

Toda pessoa sempre é as marcas

Das lições diárias de outras tantas pessoas

Gonzaguinha (1982)

Até este ano - 2019 - eu orientei 33 dissertações de mestrado e 14 teses de doutorado. Refletindo sobre todas estas produções, tento ver o que me ensinaram sobre orientar. Especialmente quando penso no doutorado, que deve preparar uma pessoa para ser um pesquisador e também para orientar pesquisas. Será que minhas orientações, meus trabalhos com meus doutorandos foram e têm sido nesse caminho? Pensando na minha própria (não) preparação para atuar na formação de pesquisadores, retomo então a experiência com a Adriana.

Agosto de 2006 - tenho o primeiro encontro com ela, que estava no 3o ano da Licenciatura em Matemática, na UFMS. Na falta de uma secretária para o Programa de Pós-Graduação em Educação Matemática da UFMS (PPGEdumat), do qual eu era a primeira coordenadora, Adriana recebeu uma bolsa permanência, no valor de trezentos reais mensais, para ajudar nessa função, por 4 horas diárias. Antes de eu convidá-la para essa função, pedi ajuda a uma amiga, também professora do então Departamento de Matemática, para indicar 
algum aluno da Licenciatura cujo perfil poderia "combinar" com minha forma de trabalho. Imediatamente, ela indicou Adriana, que não estava nem no início nem no final do curso fases dificeis para a dedicação a qualquer outra atividade - que estava com a grade curricular "em dia" e que era "organizada e séria". Fui então conhecê-la, apresentar a proposta e convidá-la para ser secretária do Mestrado em Educação Matemática.

Como secretária do PPGEdumat, Adriana descobriu outras facetas da vida em uma universidade: a burocracia dos trâmites, a Pós-Graduação, a educação matemática. Para além disso, no ano seguinte, 2007, fui sua professora de estágio, de prática de ensino e orientei sua monografia de conclusão de curso. Adriana foi, assim, naturalmente, caminhando para o mestrado em educação matemática e, ao terminar a graduação, ingressou no PPGEdumat, sendo orientada por mim e desenvolvendo pesquisa sobre a formação do professor de matemática. Posso dizer que o mestrado da Dri - como a chamamos - transcorreu sem sobressaltos: o projeto que ela apresentou no processo seletivo foi desenvolvido no curso e o produto final, sua dissertação, foi muito elogiado pela banca.

Orientá-la no mestrado não foi uma tarefa desafiadora, difícil. Claro, nenhuma pesquisa desenvolvida com seriedade é feita sem algum grau de dificuldade, porém, ela iniciou o mestrado com tanta certeza do que queria fazer e tão segura quanto a como queria fazer que meu trabalho como orientadora foi realmente orientar, sugerir e discutir artigos, corrigir textos. Sua participação foi ativa, tanto no nosso grupo de pesquisa, o Grupo de Estudos em Didática da Matemática (DDMat), como nas atividades do PPGEdumat. Eu poderia dizer que esse processo de orientação do seu mestrado me ensinou a orientar quando todas as peças do quebra-cabeça se encaixam...
Se a experiência do mestrado foi tranquila, a do doutorado não foi bem assim. No início, parecia que seria como anteriormente: tudo bem planejado, organizado e executado. o projeto submetido à avaliação do processo seletivo tinha objetivos claros e referenciais teórico e metodológico bem definidos. Só que não! Alguns meses após o início do curso e de novas leituras, ela não queria continuar percorrendo aquele caminho, mas também não sabia de nenhum outro... E então, o que fazer quando algumas peças foram perdidas? Como montar algo com o que se tem, com o que sobrou?

O que faz um orientador nessa situação? A resposta para essa pergunta totalmente genérica, eu não sei. Não tenho a menor ideia. o que posso e quero compartilhar com você, nosso leitor, é a experiência que eu vivi e que tem muitas variáveis: eu conhecia a Adriana há dez anos, éramos (somos) amigas, já havia orientado dois trabalhos de pesquisa seus: monografia de conclusão de curso e dissertação de mestrado. Tivemos experiências que foram muito além da vida acadêmica. Nem tudo foi flores, pois como toda relação mais profunda e verdadeira, há momentos de divergência, de necessidade de afastamento... Nesses, então, dez anos de convivência, Adriana conviveu comigo alguns dos momentos mais significativos da minha vida. Acho que isso se chama amizade. Mas também éramos orientadora e orientanda, e, naquele momento de "encruziIhada" da vida da Adriana, eu precisava saber agir com o amadurecimento que o papel exigia para que, assim, eu pudesse ajudá-la. E isso não significava necessariamente levá-la até o fim do doutorado, à obtenção do título, mas tentar ajudá-la a descobrir o que queria fazer. Em certos momentos e para certas pessoas, pressionar não ajuda - esse é, com certeza, um desses casos que se encaixam perfeitamente no ditado popular "se apertar, espana". Não 
contei que quando entrou no doutorado, ela já era professora concursada da UFMS e conseguiu afastamento para realizar o curso. Entre suas incertezas acadêmicas, até mesmo ser professora foi posto em dúvida. Agora posso dizer: entrei em desespero, pois precisamos tanto de professores comprometidos, que vejam, de verdade, o aluno, que reflitam sobre o seu trabalho, que se angustiem, que não vivam a profissão como se tudo estivesse indo muito bem... Eu sabia que Adriana era uma educadora desse naipe; não podia perdê-la, mas se isso não a fazia feliz, ela teria que seguir outro caminho e eu não poderia fazer absolutamente nada, a não ser ajudá-la nessa empreitada, a seguir em frente, e isso, como orientadora, mais até que como amiga. E por que digo isso? Porque uma das angústias dela nessa fase, creio eu, era me decepcionar. Ela não queria me decepcionar.

Adriana precisava respirar e buscou fazer coisas que the proporcionassem ar puro. Nesse período, com mais afinco, foi cuidar do seu jardim e, com isso, me ensinou a amar plantas. Eu, que nasci e passei a primeira infância em uma fazenda, vim a amar cuidar de plantas com ela. Em outubro de 2016, ela me ajudou a iniciar um jardim na sacada do meu apartamento. Escrevo esse texto olhando para meus vasos: hortelã, cebolinha, salsa, samambaia, jabuticabeira, guaco, menta, orquídea ... Obrigada por essas maravilhas, Dri.

E foi assim, em meio à dedicação às plantas, ao pilates, à terapia, ..., que um dia Adriana veio conversar comigo novamente sobre a tese. Definitivamente, ela não queria mais estudar didática da matemática, o campo teórico que eu estudo. Aquilo não a apaixonava mais, mas também ainda não havia um novo romance teórico. Sabia que queria continuar investigando a formação inicial de professores de matemática, porém, não como havia proposto. o que sempre a incomodou desde o tempo em que ela fazia sua graduação era a formação para ser professor.

Sentadas, nós duas, aqui onde estou agora nesse exercício de refletir sobre nosso trabaIho, pensávamos e tentávamos ver o que fazer. Foi quando sugeri que ela ampliasse seu horizonte: "Adriana, por que não vai olhar outros cursos de licenciatura pelo país, conversar com acadêmicos de outros cursos?" E a chama foi acesa novamente: seus olhos brilharam e imediatamente ela começou a viajar na proposta. 0 que fazer, onde ir, como contatar acadêmicos ....

E surge outra questão: com essa mudança de "eixo da pesquisa", qual será o referencial teórico? Nessa época, ela participava também do HEMEP, Grupo História da Educação Matemática em Pesquisa, coordenado pela Luzia, e estava se identificando com os trabalhos desenvolvidos no grupo, que versavam sobre o uso de narrativas. Como nessa nova proposta, seriam realizadas entrevistas e a ideia foi se aprofundar nessa temática. Opa! Tema fora da minha casinha!

"Dri, eu acho que você deveria ser orientada pela Lu".

"Você não quer mais trabalhar comigo?"

"Não é isso, Dri. É que talvez a Lu seja mais indicada para ajudar nesse campo; não sou da narrativa".

"Ela não pode ser coorientadora?"

E foi assim que convidamos a Luzia para trabalhar conosco e ser coorientadora da Adriana. Foi uma parceria mais que acertada. Eu aprendi muito com ela. Com as duas.

Chevallard e Ladage (2010) apresentam o paradigma questionamento do mundo em contraposição ao paradigma da visita às obras, ambos em referência a modelos de práticas pedagógicas. No paradigma de visita às obras, a obra está pronta, o professor vai apresentá - la e o aluno a visita. Já no paradigma questio- 
namento do mundo, parte-se de uma questão, mas o caminho a ser percorrido, as questões e respostas auxiliares que aparecerão até chegar a uma resposta ao problema proposto são desconhecidos e podem ser múltiplos. Nessa perspectiva, uma tese de doutorado pode ser vista como uma ação realizada à luz deste paradigma. Pode, mas nem sempre é. Minha experiência com mais de 40 orientações, mostrame que, na maioria das vezes, não é assim que acontece. Não se trata apenas de autonomia do orientando. É mais do que isso.

Quando Adriana, no doutorado, percebe que a questão colocada no projeto inicial não era mais uma questão para ela e define novo problema, dessa vez sem saber como respondê-lo, sem ideia de onde chegaria, foi um momento significativo para nós duas. Ela, decidida a problematizar um campo já tão explorado da formação de professores de matemática encontrou refúgio nos escritos sobre experiência. Eu, agora apoiada em sua leitura sobre aquilo que nos toca e nos transforma, posso dizer que vivi uma experiência do paradigma questionamento do mundo. Para desvendar os mundos das licenciaturas brasileiras, Adriana precisou em criar outras Adrianas. Ou melhor, outras Adrianas vieram à tona e começaram a dialogar todas entre si. Pode parecer - e parecia - algo meio esquizofrênico, mas ao mesmo tempo foi algo tão lúcido que cada Adriana que aparecia eu pensava: claro, é isso mesmo! Tem que ser assim!

Creio que o melhor papel de um orientador é quando ele consegue deixar florescer o outro, quando ele consegue que o outro se descubra. No dia de sua defesa, Adriana fez sua apresentação apenas falando, não usou slides ou qualquer outra ajuda. Falou, em pé, sobre sua pesquisa e conseguiu prender a atenção de todos. Assistindo essa cena eu tive a nítida impressão de estar em uma livraria, quando, no lançamento de um livro, o autor lê algu- mas de suas páginas... a diferença se fez não somente na troca da leitura pela fala, mas na troca de descrições e categorizações pela narrativa crítica de uma pesquisa, de uma pesquisadora.

\section{Referências}

BENJAMIN, Walter. Magia e técnica, arte e política: ensaios sobre literatura e história da cultura. Tradução de Sergio Paulo Rouanet. São Paulo: Editora Brasiliense, 1987. (Obras Escolhidas, I).

BOLÍVAR, Antonio; DOMINGO, Jesús; FERNÁNDEZ, Manuel. La investigación biográfico-narrativa em educación: enfoque y metodología. Madrid: La Muralla, 2001.

CHEVALLARD, Yves; LADAGE, Caroline. Enquêter pour connaître. L'émergence d'un nouveau paradigme scolaire et culturel à l'âge de l'Internet. Journée de réflexion sur le thème «Une approche anthropologique du didactique». Université de Liège, Belgique, 2010. Disponivel em : <http://yves.chevallard.free. $\mathrm{fr} / \mathrm{spip} / \mathrm{spip} /$ article.php3?id_article=196>. Acesso em: 05 out. 2018.

CLARETO, S. M. Na travessia: construção de um campo problemático. In: CLARETO, Sônia Maria; ROTONDO, Margareth Aparecida Sacramento; VEIGA, Ana Lygia Vieira Schil da. Entre composições: formação, corpo e educação. Juiz de Fora: Editora UFJF, 2011. p. 17-32.

GONZAGUINHA. Caminhos do coração. Formato LP/ CD. Gravadora: EMI-Odeon. 1982. Disponivel em: <https://immub.org/album/caminhos-do-coracao>. Acesso em: 10 nov. 2018.

LARROSA, Jorge. Literatura, experiência e formação: uma entrevista com Jorge Larrosa. In: COSTA, Marisa Vorraber (Org.). Caminhos Investigativos I: novos olhares na pesquisa em educação. Rio de Janeiro: Lamparina Editora, 2007. p. 129-156.

LARROSA, Jorge. Notas sobre a experiência e o saber da experiência. Revista Brasileira de Educação, Rio de Janeiro, n. 19, p. 20-28, jan./fev./mar./abr. 2002. Disponivel em: <http://www.scielo.br/pdf/rbedu/ n19/n19a02.pdf>. Acesso em: 15 set. 2018. 
LARROSA, Jorge. Tremores: escritos sobre experiência. Tradução de Cristina Antunes e João Wanderley Geraldi. Belo Horizonte: Autêntica Editora, 2016.

SKLIAR, C. Pedagogia (improvável) da diferença: e se o outro não estivesse aí? Tradução de Giane Lessa. Rio de Janeiro: DP\&A, 2003.
SOUZA, Luzia Aparecida; SILVA, Carla Regina Mariano. Narrativas e história oral: possibilidades de investigação em Educação Matemática. São Paulo: Livraria da Física, 2015.

Recebido em: 10.01.2019

Aprovado em: 02.04.2019

Adriana Barbosa de Oliveira é Doutora em Educação Matemática pela Universidade Federal de Mato Grosso do Sul, Universidade Federal de Mato Grosso do Sul, Professora Adjunta, membro do HEMEP - Grupo História da Educação Matemática em Pesquisa. e-mail: drideoliveira7@gmail.com

Rua Monte Azul, 1237, Vila Marli, Campo Grande, MS, CEP 79117020. (67) 999331233

Marilena Bittar é Pós-Doutora em Educação Matemática pela Universidade Grenoble-Alpes, Universidade Federal de Mato Grosso do Sul, Professora Titular, Líder do DDMat - Grupo de estudos em Didática da Matemática. e-mail: marilenabittar@gmail.com

Rua Brasil, 786, apto. 1203, Centro, Campo Grande, MS, CEP 79002480. (67)992580150

Luzia Aparecida de Souza é Doutora em Educação Matemática pela Universidade Estadual Paulista, campus de Rio Claro, Universidade Federal de Mato Grosso do Sul, Professora Adjunta e Líder do HEMEP - Grupo História da Educação Matemática em Pesquisa. e-mail: luapso@gmail.com

Rua Maria Justina de Souza, 59, Bairro Rita Vieira, Campo Grande, MS, CEP 79052100. (67)981387437 